\title{
Temperature and oxygen effects on oxidation-induced fragmentation of
} soot particles

5
${ }^{a}$ Dipartimento di Ingegneria Chimica, dei Materiali e della Produzione Industriale, Universita` degli Studi di Napoli Federico II, Italy

${ }^{\mathrm{b}}$ Department of Chemical Engineering, University of Utah, Salt Lake City, UT, USA

* Corresponding Author. Address: Department of Chemical Engineering, University of Utah, Salt Lake City, UT, USA. Fax: +1 801-585-9291. E-mail address: 


\section{ABSTRACT}

45 In this work soot oxidation induced-fragmentation is modeled by using a Multi-Sectional 46 approach. The model has been developed previously and applied successfully, confirming the

47 role of oxidation-induced fragmentation in soot burnout under different combustion conditions.

48 The Multi-Sectional model was used without further modification to understand the mechanism

49 governing the oxidation-induced fragmentation of soot aggregates and particles by modeling

50 particle size distributions (PSDs) previously measured in a two-stage burner under a wide range

51 of temperature and in both fuel-lean and fuel-rich overall conditions. The model was able to

52 reproduce the experimental data in all the investigated conditions both in terms of PSDs and total

53 mass of oxidized particles.

54 An analysis of model results suggested that when temperature decreased, small particles

55 produced by oxidation-induced fragmentation could not be completely oxidized and, thus, could

56 be emitted; on the other hand, when temperature increased, the global oxidation process was

57 more effective and small particles were oxidized and reduced in number concentration.

58 When studying fuel rich conditions, the model predicted that the local presence of a relevant 59 oxygen concentration caused the oxidation-induced fragmentation mechanism, producing small 60 particles, which could eventually be emitted.

61 Finally, a sensitivity analysis was conducted on oxidation-induced fragmentation indicating

62 that aggregate fragmentation controlled soot burnout whereas particle fragmentation was

63 responsible for small particle formation. However, the sensitivity analysis also suggested that

64 both mechanisms were needed for the correct prediction of the evolution of PSDs. 


\section{KEYWORDS}

68 Multi-Sectional method, oxidation-induced fragmentation, soot, particle size distribution, two-

69 stage burner

70 


\section{1. Introduction}

72 Over the years, soot emission mechanisms have been extensively studied to improve

73 combustion processes [1-5] and, thus, reduce their impact on human health [6,7] as well as on

74 the environment [8]. Most studies have been devoted to the understanding of soot inception, i.e.,

75 the process which leads from gas-phase, high molecular mass species, such as PAHs, to the

76 formation of the first particle or condensed phase compound [9-13]. Despite these efforts,

77 inception remains the least understood mechanism in combustion-derived particle formation,

78 whereas there is a larger convergence in the combustion community on the surface growth

79 mechanism and the dynamics of particles and large aggregates [14,15].

80 Particle formation is not the only mechanism that contributes to the determination of the final

81 particle emissions. In real combustion devices, the oxidation processes play a determinant role

82 for particle emissions. In fact, most of the emitted particles could be those escaping oxidation,

83 usually during the last part of the combustion process within combustion devices or in the after-

84 treatment system [16-19]. As a result of soot oxidation mechanism studies, semi-empirical

85 reaction rates are used in a large number of models [20-23]. It is accepted that soot can be

86 oxidized when it reacts with molecular oxygen $\left(\mathrm{O}_{2}\right)$ and hydroxyl radical $(\mathrm{OH})$. Two kinetic

87 expressions to account for the soot oxidation via $\mathrm{O}_{2}$ and $\mathrm{OH}$ have been proposed by Nagle-

88 Strickland-Constable (NSC) [24] and Neoh et al. [25], respectively. Although these reaction rates

89 have been widely used, and result in fair agreement with experimental data, a deeper

90 comprehension of the oxidation phenomena of combustion-generated particles is needed.

\section{1.1. Phenomenology of oxidation-induced fragmentation}

92 While oxidation is responsible for the soot burn-out, particle aggregates can be attacked by 
93 oxidant species such that the structure weakens and the aggregates subsequently break apart.

94 This process, oxidation-induced fragmentation, has been noted in the study of Neoh, Howard and

95 Sarofim [26]. However, despite the novelty and possible impact on soot emission in combustion,

96 oxidation-induced fragmentation has not been fully incorporated into soot models, with some

97 exceptions. Recently, due to new studies conducted on a two-stage burner similar to Sarofim and

98 Neoh's [27-31], and due to the increased number of details now possible in soot combustion

99 models, oxidation-induced fragmentation can be taken into account [32-34].

100 The study of the oxidation process and, in particular, of oxidation-induced fragmentation is

101 difficult since oxidation is usually competing with formation and growth of soot particles. This

102 overlapping of effects does not allow a straightforward approach to the study of the oxidation.

103 The two-stage burner proposed by Sarofim and Neoh [26] and this group [27-31,35] isolates

104 oxidation from formation, allowing more complex and hidden phenomena to be studied, such as

105 oxidation-induced fragmentation. Further details of the two-stage burner can be found in 106 previous experimental work [35].

107 Experimental investigations, mainly conducted on a two-stage burner, have shown that 108 during the oxidation of soot particles in high-temperature environments, fragmentation of 109 aggregates and even fragmentation of primary particles may occur [27,30,31]. The evolution of 110 particle size distributions (PSDs) obtained with two-stage burner setup has constituted a 111 benchmark for the modelers to approach the problem and the agreement of model predictions 112 with results produced in the two-stage burner represents an achievement.

113 Several research groups have proposed phenomenological and numerical models to describe 114 oxidation-induced fragmentation using different approaches [32-34,36,37]. Starting from 115 experimental evidence of the internal structure of soot particles as well as appropriate 
116 experiments to isolate the contribution of oxidation and indeed of oxidation-induced

117 fragmentation, a general sketch of the processes taking place can be drawn. The brief discussion

118 below serves as an introduction to the phenomenological model of oxidation-induced

119 fragmentation.

120 Particles can be attacked by several oxidant species, depending on the flame conditions.

121 Since other species, i.e., $\mathrm{O}, \mathrm{CO}, \mathrm{CO}_{2}$, and $\mathrm{H}_{2} \mathrm{O}$, usually have a negligible contribution to

122 oxidation under most combustion conditions present in real and lab-scale devices and

123 particularly in the investigated conditions [25,38,39], only $\mathrm{OH}$ and molecular oxygen, $\mathrm{O}_{2}$, are

124 studied here. The two oxidants differ regarding reactivity and of relative abundance in the

125 combustion environment, again depending on the combustion conditions. Under fuel rich

126 conditions, due to its relatively high abundance, $\mathrm{OH}$ is considered the most important species

127 contributing to the oxidation process in competition with the formation and growth pathways. On

128 the other hand, molecular oxygen $-\mathrm{O}_{2}$, plays a determinant role in fuel lean conditions. In fact,

129 under these conditions, $\mathrm{O}_{2}$ is abundant, up to the order of percentages in mole fraction, before

130 and after the flame front, and its contribution to the global oxidation rate becomes important

131 [40]. In fuel lean conditions, particle formation does not start, and thus no soot particles are

132 formed; however, due to gas recirculation, typical of turbulent and diffusion-controlled

133 combustion, soot particles can be formed in fuel-rich conditions and pass through fuel lean

134 conditions where they can be eventually oxidized $[41,42]$.

135 Oxidation by $\mathrm{OH}$ and $\mathrm{O}_{2}$ are considered surface processes able to subtract carbon atoms from

136 the particles. Oxidation-induced fragmentation of particles can occur if the oxidizing species

137 penetrate the aggregates or even the particles and remove $\mathrm{C}$ atoms from a weak point causing the

138 break-up of the large aggregates and particles into smaller aggregates and smaller particles 
140 In addition, stepwise splitting up of large aggregates because of oxidation-induced

141 fragmentation can lead to smaller aggregates formed by a limited number of primary particles.

142 Fragmentation can also involve primary particles where internal burning fragments a single 143 particle into smaller particles. The process can continue producing very small molecular clusters.

144 Oxidation-induced fragmentation can be distinguished into two mechanisms: aggregate 145 fragmentation and single particle fragmentation. The fragmentation of aggregates occurs if the 146 carbonaceous material at the contact points of the primary particles is oxidized destroying the 147 "bridges" holding together the primary particles. Recently, our group has shown that these 148 "bridges" are more reactive as compared to the rest of particle surface [30,31].

149 In the fragmentation of single particles, particles fragment into smaller particles. Previous 150 work on coal has shown that as internal structure is destroyed, and porosity increases, the particle 151 will eventually break apart [43,44]. Neoh et al. [26] and Echavarria et al. [27,28] support a 152 similar mechanism for soot particles, finding in their experiments the appearance of a 153 considerable number of sub-10nm particles during particle oxidation. These sub-10nm particles 154 have been linked with oxidation-induced fragmentation since a particle shrinking model could 155 not explain their formation.

156 Oxidation-induced fragmentation as described above has recently been incorporated into a 157 Multi-Sectional model [33,45-48] for particle evolution in flames which discretizes the 158 combustion aerosol on the basis of the number of $\mathrm{C}$ and H-atoms and the morphology: single 159 molecules, molecular clusters and primary particles, and particle aggregates. In contrast to other 160 modeling approaches [49], the Multi-Sectional model is the only one that may account for both 161 aggregate and primary particle fragmentation. The model has been tuned using the experimental 
162 data produced by Echavarria et al. [27,28] on the two stage burner and has been used to simulate

163 diffusion flames of ethylene increasing the predictions of particle volume fractions and sizes

164 with respect to previous models in which oxidation induced fragmentation was not included [20-

$16524,49-57]$.

166 The results produced by Echavarria et al. in the two-stage burner were limited [27,28] in

167 terms of temperature and mixing conditions. More recently this group, using the same

168 experimental setup, has published a set of data which cover the evolution of PSDs during the

169 oxidation process over a wide range of temperatures and both fuel-rich and fuel lean overall

170 conditions [30,31,35]. In the present work, the Multi-Sectional model was used without any

171 further adjustment to reproduce the evolution of size distribution and give insight into the role

172 and the relative importance of oxidation-induced fragmentation.

173

174 2. Experimental methods

175 The data used for this study was previously generated, but a brief overview of the 176 experimental apparatus follows. A two-stage burner designed after the apparatus of Neoh [58]

177 was used to generate soot in a fuel-rich premixed flame, which served as the first stage. The soot 178 was then burned in a secondary, premixed burner. Details are given in Ghiassi, et al. [59]. In the 179 first-stage burner, air and fuel (ethylene $>99.99 \%$ ) were added to the bottom of a 5-cm ID 180 stainless steel chamber under $\mathrm{U}_{1}=3.77 \mathrm{~cm} / \mathrm{s}$. Complete mixing occurred over a thick bed of 181 glass beads, and the flame was stabilized over a tube bundle through which the mixture passed in 182 laminar flow. The overall equivalence ratio () is defined by the ratio of fuel to total oxygen 183 (oxygen injected into the bottom and top burners) fed into the burner over the stoichiometric 184 ratio. 
186 in the second-stage burner. Nitrogen $\left(\mathrm{N}_{2}\right)$, argon $(\mathrm{Ar})$ and helium $(\mathrm{He})$ were used to produce fuel

187 lean flames on the top burner. Argon and helium were chosen to achieve higher and lower 188 temperature than nitrogen, respectively, which was the reference case. In order to achieve 189 different oxygen enrichment, on the top burner, a flame with a fuel-rich equivalence ratio was 190 also investigated. Values of the first burner and overall equivalence ratios, for all the conditions, 191 are reported in Table 1.

192 Temperature profiles were measured using a $0.02032 \mathrm{~cm}$ diameter, type-B thermocouple. The 193 radiation correction for the temperature was similar to that of McEnally et al. [60]. A Scanning 194 Mobility Particle Sizer (SMPS), which consisted of a TSI 3080 classifier and a 3025 ultrafine 195 condensation particle counter, was used with a 3085 nano-DMA (differential mobility analyzers) 196 to measure particle size distributions (PSDs) in the size range from 3 to $140 \mathrm{~nm}$. The SMPS 197 sampling system was similar to that of Zhao et al. [61,62] with some minor changes in probe size $198(\mathrm{OD}=1.1 \mathrm{~cm})$ and pinhole diameter $(0.024 \mathrm{~cm})$. Dilution ratios were in the range of $10^{3}$ to $10^{4}$ 199 which minimized particles losses and coagulation in the sampling system. Corrections for 200 diffusion losses and coagulation along the sampling line were carried out following the 201 procedure presented by Minutolo et al. [63]. $\mathrm{H}_{2}, \mathrm{O}_{2}, \mathrm{CO}$, and $\mathrm{CO}_{2}$ were sampled using a water202 cooled probe (0.2-cm ID) and analyzed by online gas chromatography (VARIAN, CP-4900 203 Micro GC).

\section{3. Chemical kinetic modeling}

207 The kinetic mechanism of molecular growth and oxidation was based on the lumping of 
208 high-molecular-mass species by their number of $\mathrm{C}$ and $\mathrm{H}$ atoms and by their state of aggregation,

209 i.e., single molecules, clusters of molecules (primary particles) and aggregates of primary

210 particles, described in detail in previous publications [33,34]. The lumped scheme was coupled

211 with a mechanism of oxidation and pyrolysis of the hydrocarbon fuels which was extensively

212 validated in premixed and diffusion flame $[33,34,46-48]$.

213 Starting from pyrene, all of the compounds with larger molecular masses were considered as

214 lumped species. The reactions accounting for molecular weight growth and oxidation were

215 treated on the basis of similarity with gas-phase reactions involving PAHs. Lumped molecular

216 species in their stable and radical form were accounted for. The collision frequency of the

217 chemical reactions was evaluated by kinetic theory. Although the reactions for the lumped

218 species cannot be considered as elementary reactions, this approximation was the primary

219 foundation of the sectional approach and it was applied to all the particle phase reactions.

\subsection{Oxidation-induced fragmentation: reaction rate calculations}

221 Model details of oxidation and particularly oxidation-induced-fragmentation processes have

222 been extensively published through the years [33,34,46-48]; however, for the sake of 223 completeness of the discussion, the key features, how they have been designed and specifically 224 treated by the Multi-Sectional model, are detailed below.

225 In the Multi-Sectional model, all the lumped species can be oxidized in their stable and 226 radical form by $\mathrm{OH}$ and $\mathrm{O}_{2}$, respectively, in similarity with the PAH oxidation for which some 227 studies are present in literature. Both $\mathrm{OH}$ and $\mathrm{O}_{2}$ oxidation were considered in the subtraction of 228 carbon atoms from the lumped species, reducing their total amount. Since these processes, 229 similar to the growth process, were considered as surface processes, they were modeled taking 230 into account the collision rate based on the size of the lumped species. The determined reaction 
231 rates have been tested in premixed and laminar diffusion flames, giving fair agreement in fuel-

232 rich premixed conditions but failing to match the complete burnout in a non- smoking diffusion

233 flame [57]. In addition, the consideration of oxidation as only a surface reaction was not able to

234 reproduce the evolution of particle size distributions during the soot oxidation measured in the

235 two-stage burner [33]. To improve mechanism predictions and to implement the

236 phenomenological model, oxidation-induced fragmentation was introduced.

237 Fragmentation of aggregates into smaller aggregates, and eventually into single particles, and

238 the breaking apart of a single particle forming smaller ones were considered. As described in the

239 introduction, aggregates can fragment if oxidation occurs at the contact points of the primary

240 particles. Oxidation of interstitial material is still a surface reaction, directed toward a selected

241 zone of the aggregate. However, gas-phase oxidant species have to access to the bridge between

242 the particle which might be "hidden" by the fractal structure and thus not immediately

243 accessible. Hence, in the version of the Multi-Sectional model used in the present work,

244 molecular oxygen, $\mathrm{O}_{2}$, was considered the only species able to fragment the aggregates. $\mathrm{OH}$ is

245 also likely to be oxidizing the bridge sites, concurrently with the surfaces. However, since the

246 reaction is so fast, it is difficult to ascertain the contributions of $\mathrm{OH}$ and further study is needed.

247 Starting from these considerations about aggregate fragmentation, the reaction rate of

248 oxidation-induced fragmentation of aggregates was related to the total $\mathrm{O}_{2}$ oxidation rate. A

249 fragmentation event was modeled to occur after the removal of a fraction $\delta$ of $\mathrm{C}$-atoms from the

250 particles close to the point of contact between particles. The number of contact points in the

251 aggregates can be estimated by dividing the total mass of the aggregates by the average mass of

252 the primary particles. It was considered that there were more than two $\mathrm{C}$ - atoms holding the 253 aggregate together. Given this, the fraction $\delta$ of $\mathrm{C}$-atoms that must be removed to cause 
254 fragmentation is expressed as

255

256

$\delta \mathrm{C}=\alpha * n_{C}{ }^{P}$

257 where $n_{C}{ }^{P}$ is the total number of carbon atoms per primary particles and $\alpha$ is the fraction of the 258 total number of C-atoms constituting the primary particles to be removed.

259 Of course, not all the oxidation events occur on the contact points. The probability that the 260 oxidation by $\mathrm{O}_{2}$ occurred at a weak link between two particles is equal to the inverse of the 261 number of active sites for $\mathrm{O}_{2}$ oxidation on the particle surface:

262

263

$n_{\text {active sites }}=\chi \pi d_{P}^{2}$

264 where $\chi=1.7 \times 10^{19} \mathrm{~m}^{-2}$ [64] is the number of sites per unit area and $\pi d_{P}^{2}$ is the primary particle 265 surface area. Each oxidation event removed two carbon atoms. The fragmentation rate of 266 aggregates is then given by:

267

$k_{f}=k_{O 2 *}\left(n_{P}-1\right) /\left(\left(\chi_{*} \pi_{*} d_{P}^{2}\right) * \delta \mathrm{C}\right)$

where $d_{P}$ is the size of the primary particles and $n_{P}$ is the number of primary particles in the

270 aggregate which can be calculated as $n_{P}=n_{C}{ }^{A} / n_{C}{ }^{P} \cdot n_{C}{ }^{A}$ is the number of C-atoms in the aggregate.

271 In the model $d_{P}$ is considered to be $20 \mathrm{~nm}$. This choice has been used in prior studies [65-67];

272 however, it does not imply that all the primary particles are $20 \mathrm{~nm}$ or that the model can be

273 applied under only these conditions. A primary particle with $d_{P}$ of $20 \mathrm{~nm}$, and the corresponding

274 number of $\mathrm{C}$-atoms was used to estimate the number of contact points in an aggregate and

275 resulted in a manageable expression for the reaction rate of the oxidation induced fragmentation 276 (Eq. 3). 
278 fragmentation of a single particle. HR-TEM images of young soot particles suggest that clusters

279 of aromatic compounds appear to be the major constituents of primary particles [12]. An average

280 size of less than $1 \mathrm{~nm}$ can be retrieved from HR-TEM images and these structures are often

281 referred as Basic Structure Units (BSUs). Although an overall compact structure could be

282 hypothesized for these particles, HR-TEM images suggest that single particles prefer to arrange

283 in more loose structures in which these BSUs are randomly organized and are separated from

284 each other by "pores" having a length of the same order of magnitude of the BSU [12]. Some

285 oxidant species may diffuse into these pores. In fact, oxidant can erode a particle on its surface,

286 but it can also penetrate the pores internally to oxidize the particle. The possibility that the

287 reaction takes place only on the surface versus consideration of both surface and internal reaction

288 was linked with the ratio between the reaction time and the diffusion time of the oxidant species

289 through the pore. Once again, molecular oxygen would likely play this role and penetrate the

290 particles burning internally due to its slower burning rate. To correctly evaluate the reaction rate

291 relatively of molecular oxygen in comparison with its diffusion into the pores of the structure,

292 some assumptions on particle structure were made. The length of the aromatic island visible in

293 the HR-TEM images is $1 \mathrm{~nm}$ on average, i.e., an aromatic compound constituted by 20-25 C-

294 atoms. The number of aromatics in well-organized structures was always on the order of 4-5

295 stacked planes at a distance of about $0.35 \mathrm{~nm}$. To evaluate the size of the pores and oxygen

296 diffusion, a length of the same order of magnitude as the BSU (1nm) and a width of about 0.5

$297 \mathrm{~nm}$ were considered. Although larger pores can be found in the particles, these conservative

298 values were more typical of aged soot. Knudsen diffusion of molecular oxygen in the pores was

299 derived from the kinetic theory of gases by replacing the path length with the pore diameter and 
300 the rate of the surface oxidation by $\mathrm{O}_{2}$ for a range of particles. By comparing the characteristic 301 diffusion time with the characteristic reaction time of surface oxidation with $\mathrm{O}_{2}$ at a flame 302 temperature of $1500 \mathrm{~K}$ and with the geometrical characteristics of the pores reported above, the 303 process is in the reaction limited regime, leading to the hypothesis that diffusivity of $\mathrm{O}_{2}$ is not the 304 controlling step in the internal oxidation of particles. On the other hand, because of the faster 305 reactivity of $\mathrm{OH}$, it does not penetrate the pores but oxidizes the particle on its surface. This 306 evaluation was not dramatically affected by particle structure assumptions, i.e. fringe length or 307 pore size. As long as these parameters do not change by orders of magnitude, molecular oxygen 308 diffusion into the pores of primary particles is faster than reaction rate.

309 When oxidation by $\mathrm{O}_{2}$ occurs in the depth of the pores, the particle can fragment into two 310 parts by again considering the removal of a fraction $\delta$ of $\mathrm{C}$-atoms within the particles after the 311 penetration within the pore. This number of carbon atoms is given here by $\delta \mathrm{C}_{\text {pores }}=\beta_{*} n_{C}{ }^{P}$

314 where again $n_{C}{ }^{P}$ is the total number of carbon atoms per primary particles and $\beta$ represents the 315 fraction of $\mathrm{C}$-atoms in the particle that must be removed to cause fragmentation of the particle.

316 The number of pores present in the structure, $n_{\text {pores }}$, can be evaluated from the volume of a 317 single pore relative to the particle volume. It can be considered that for each BSU one pore of 318 similar dimension exists. The number of BSUs constituting a particle, $n^{B S U}$, is obtained by 319 dividing the number of $\mathrm{C}$-atoms in the particle by the number of C-atoms constituting the BSU. 320 The number of $\mathrm{C}$-atoms in the BSU, $n_{C}{ }^{B S U}$, is obtained from the above reported HR-TEM images; 321 the BSU is estimated to contain four aromatic molecules each of $25 \mathrm{C}$-atoms. Hence, 
$n^{B S U}=n_{\text {pores }}=n_{C}{ }^{P} / n_{C}^{B S U}$.

323 Finally, just a fraction of the entire pore surface was considered to be a weak point for the

324 oxidation-induced fragmentation, namely, the area at the bottom of the pore, $A^{\text {pores active }}$. For 325 cylindrical pores with a depth $L$, of the same order of magnitude of the $B S U(1 \mathrm{~nm})$ and diameter, $326 w$, of about $0.5 \mathrm{~nm}$, the internal surface area of the pores was obtained:

$A^{\text {pores active }}=\left(\pi w^{2} / 4 /\left(\pi w L+\pi w^{2} / 4\right)\right)$.

327 The fragmentation rate for the particles is then:

328

$k_{f}=k_{O 2 *}\left(\pi w^{2} / 4 /\left(\pi w L+\pi w^{2} / 4\right)\right) * \mathrm{n}_{\text {pores }} /\left(\delta \mathrm{C}_{\text {pores }}\right)$

330 The model presented relies on two parameters, namely $\alpha$, i.e., the fraction of the total number

331 of $\mathrm{C}$-atoms constituting the primary particles to be removed to cause aggregate fragmentation, 332 and $\beta$, i.e., the fraction of $\mathrm{C}$-atoms in the particle that must be removed to cause fragmentation of 333 the particle.

$334 \alpha$ and $\beta$, were not assigned a priori, but were retrieved from a sensitivity analysis of the 335 model predictions against the experimental data of Echavarria et al. [27,28]. Using values of $\alpha=$ $3360.01(1 \%$ of the total number of $\mathrm{C}$-atoms in the primary particle) and $\beta=0.05(5 \%$ of the total 337 number of $\mathrm{C}$-atoms in the particle) the model was able to reproduce both the total burn out rate 338 and the change in shape of PSDs quite well for an overall equivalence ratio of 0.8 . The model 339 predicted the oxidation-induced fragmentation and these values were not changed in this work.

341 The model used the experimental temperature profile, the gas chromatograph (GC) results at 342 the exit of the top burner, and the initial PSDs as input. These inputs were used to avoid initial 
343 discrepancy between the model and the experimental data, which could lead to misinterpretation

344 of the results. Particles larger than 20nm, based on experimental PSDs, were considered

345 aggregates of primary particles whereas particles smaller than $10 \mathrm{~nm}$ were considered single

346 particles. Particles of an intermediate size were hypothesized to be a mixture both particles and

347 aggregates; a linear interpolation was used to determine the number of aggregates and the

348 number of single particles to input to the model. This assumption was made in agreement with

349 experimental findings from a different experimental setup $[65,66]$ as well as results obtained in

350 two-stage burner experiments [25-28,30,31]. The fraction of particles below $20 \mathrm{~nm}$ was relatively

351 small in terms of mass and number concentration. Hence, the choice of considering these two

352 classes of particles (20nm and $10 \mathrm{~nm}$ ) as single particles or as aggregates did not significantly

353 influence the results. A sensitivity analysis, not reported in this paper, confirms this assumption.

354 In the present model, aggregates formed by particles with sizes on the order of 2-4 nm were not

355 considered. Discussion on this point is reported in $[33,44-46]$ where the model is explained in 356 detail. It is worth mentioning that experimental data suggest that particle sizes as large as $7-10 \mathrm{~nm}$

357 are needed to form aggregates $[17,68,69]$.

358 The SMPS does not distinguish between particles and aggregates as it measures only the 359 mobility diameter. In this regard, the choice regarding the first part of PSDs has less importance.

360 In the future, and for better comparison, the use of an auxiliary technique, such as HR-TEM, 361 would help explain this point further.

\section{4. Results and discussion}

364 In this section both experimental results and model predictions are presented: first, those 365 regarding the effect of temperature on oxidation-induced fragmentation in a fuel-lean 
environment; and, second a fuel-rich case was explored. These results are compared with those

367 obtained in fuel-lean conditions to show similarities and differences. Finally, the model was used

368 to distinguish between the relative contributions of different reaction pathways of oxidation-

369 induced fragmentation to the global soot burnout and the change in PSDs. While some of the

370 experimental data have been published elsewhere [30], the PSDs have not. Modeling attempted

371 to shed light on the role of oxidation-induced fragmentation in total burn out and on the

372 formation of sub-10nm particles during soot oxidation. This latter aspect has been clearly seen

373 experimentally; however, a definitive explanation has not been achieved.

\subsection{The effect of temperature on fragmentation(experiments with $\mathrm{He}, \mathrm{Ar}$, and $\mathrm{N}_{2}$ )}

375 To investigate the effect of the temperature on oxidation-induced fragmentation, the oxidant

376 stream fed to the second (top) burner was diluted with different species. In particular, as shown

377 in Table 1, nitrogen $\left(\mathrm{N}_{2}\right)$ argon $(\mathrm{Ar})$ and helium $(\mathrm{He})$ were chosen to dilute the oxygen $\left(\mathrm{O}_{2}\right)$, to

378 obtain a fixed diluent/oxidant molar ratio of 79/21, similar to air and also similar to other cases

379 previously investigated $[27,28,30]$. Since the number of moles in the second burner has been

380 kept constant, the velocity of cold gas was constant. The flame obtained by using $\mathrm{N}_{2}$ as a diluent

381 is presented as a reference case for two reasons. First, the use of $\mathrm{N}_{2}$ effectively results in a flame

382 with a temperature intermediate between those produced with Ar (higher temperature) and He

383 (lower temperature). Second, $\mathrm{N}_{2}$ has been used in previous works. For all the investigated cases,

384 the conditions of the flame in the first burner was kept constant (see details in Table 1), as the

385 first burner was used to "feed" a determined particle size distribution to the top burner.

386 Temperature profiles for the three different diluents are shown in Figure 1 [30]. As seen in

387 the figure, peak temperature differs by only approximately $100 \mathrm{~K}$ between the cases; in contrast, 388 quite remarkably, oxidation-induced fragmentation is significantly different as reported below. In 
addition, the position of the flame front shifts within $1.5 \mathrm{~mm}$ in the three cases: this difference has

390 been found to be of a minor effect, as discussed further below.

391 Measurements of the major constituent gas-phase concentrations, by using on-line GC 392 analysis, are reported in Fig. 2 versus the residence time in the flame. The residence time was 393 calculated by taking into account the thermal expansion due to temperature and the variation in 394 the number of moles. In fact, although the cold gas velocity in the second burner was kept 395 constant, the differences in temperature profiles caused slight changes in the effective velocity 396 profiles along the flame and in the residence time in each flame. The use of residence time 397 instead of the height above the burner takes these small differences into account, allowing a 398 better comparison.

399 Figure 2 also reports the model predictions for the different cases investigated. The inputs for 400 the model were both the initial gas composition and the temperature profiles. However, due to 401 the perturbation of the probe used to sample the gas from the flame, the modeled profiles were 402 shifted $2.5 \mathrm{~mm}$ away from the burner to match the experimental gas profiles. This procedure was 403 necessary since the probe locally cools down the flame, slowing down the chemical reactions 404 and thus moving the reaction zone downstream. The shift occurred before the conversion from 405 the height above the burner to the residence time. The shift was found to be the same for all the 406 flames and was kept constant. This procedure was applied several times in previous studies 407 where gas concentration, as well as experimental PSDs, was compared to model predictions [70]. 408 Figure 2 shows that, due to overall lean conditions, the $\mathrm{O}_{2}$ concentration after the first reaction 409 zone, decreased, approaching a final value between 6 and $8 \%$. More important, in all the 410 investigated conditions, the gas concentration profiles were quite similar, suggesting that the 411 effect of their differences on the oxidation-induced fragmentation was negligible and that 
412 temperature played a dominant role. Model results, also reported in the figure, were in fair 413 agreement with experimental data.

414 In Fig. 3 the experimental particle size distributions (PSDs) collected in the second burner 415 are reported together with model predictions. The predicted PSDs matched fairly well with the 416 experimental data. Again, the model parameters, i.e., the fraction of the total number of C-atoms 417 constituting the primary particles to be removed to cause aggregate fragmentation, and the 418 fraction of $\mathrm{C}$-atoms in the particle that must be removed to cause fragmentation of the particle, 419 were been changed from those based on different conditions, but the same experimental set up. 420 The ability of the model to predict PSD evolution at different temperature conditions validates its 421 use for other combustion conditions.

422 Experimental data suggest that the temperature had a major effect on oxidation-induced 423 fragmentation. Looking at the reference case, $\mathrm{N}_{2}$ (center column in Fig 2), the initial PSD was 424 centered around 40nm with a small number of particles below 10nm, and the complete absence 425 of particles with diameters below $4 \mathrm{~nm}$. When the temperature and, correspondingly, the 426 oxidation rate, increased, an increase in the number concentration of particles smaller than $5 \mathrm{~nm}$ 427 was observed $(2.4 \mathrm{~mm})$. At the same time, a decrease of large particles (probably aggregates), 428 both in concentration and size, was observed. The burning of large and/or small structures 429 continued until they were fully oxidized at the end of the flame $(4.8 \mathrm{~mm})$, and were no longer 430 detected due to limits of the experimental apparatus. Note that the measured PSDs started at $4313 \mathrm{~nm}$, whereas the model indicated the presence of particles as small as $2 \mathrm{~nm}$ in relevant number 432 concentration. These particles, although negligible in mass, were dominant in the PSDs.

433 By increasing the temperature, the Ar case (left column in Fig. 2), all reaction rates were faster, 434 and the evolution of PSDs was harder to follow. In fact, since oxidation-induced fragmentation 
435 can be seen as a particular event of the global oxidation, an increase in temperature increased the

436 reaction rates of both processes. Accordingly, in the Ar case, a rise in number concentration of

437 particles smaller than $5 \mathrm{~nm}$ was clearly visible at $2.4 \mathrm{~mm}$, with hints of this rise just before and

438 after this location. The shorter appearance of the peak of these small particles produced by

439 oxidation-induced fragmentation was mainly because they were oxidized too fast to appear

440 clearly and persist in the flame, as compared with the $\mathrm{N}_{2}$ case. Similarly, the reduction in size

441 and concentration of the larger particles was quicker in the Ar case, and a complete burn-out was

442 reached at the end of the flame.

443 Interestingly, the He case (right column in Fig. 2) showed an opposite behavior; the

444 temperature decrease resulted in incomplete oxidation of small and large particles. In fact,

445 particles smaller than $5 \mathrm{~nm}$ produced by oxidation-induced fragmentation persisted all along the

446 flame, and complete burnout was not reached. This result shows how the global oxidation rate

447 was sensitive to the oxidation-induced fragmentation and how, in certain conditions, smaller

448 fragments were produced from larger particles which cannot be completely oxidized.

449 Some considerations on the nature of the small particles can be extrapolated from this 450 analysis. The small particles, less than $10 \mathrm{~nm}$, were formed from the break-up of primary 451 particles meaning that their features, i.e., the internal structure down to the atomic level, could be 452 more likely associable to a "nano-soot" rather than a large aromatic structure similar to an 453 ensemble of PAHs with loose interconnections, which is typically found during the formation 454 process. These differences could result in a different reactivity toward human health and/or 455 toward after-treatment systems. Further studies on these particles will be needed to investigate 456 more deeply their nature.

457 In order to better show the effect of oxidation-induced fragmentation on the number 
458 concentration, Fig. 4 (left panel) shows the integrated particle number as a function of residence

459 time for particles between 3 and $10 \mathrm{~nm}$. The highest temperature case, Ar, showed the smallest

460 rise in number concentration, followed by $\mathrm{N}_{2}$ and, finally, $\mathrm{He}$ - the lowest temperature case. This

461 again is evidence on the competition between oxidation-induced fragmentation, producing small

462 particles in high number concentration, and global oxidation process that reduces their amount.

463 Since the diluents have different thermo-fluid dynamic characteristics, there were also slight

464 differences in the combustion environment and initial PSDs. Fig. 4 (right panel) illustrates the

465 model results for the integrated number concentration where the experimental temperature

466 profiles from Fig. $4 \mathrm{a}$ were used, but $\mathrm{N}_{2}$ replaced $\mathrm{Ar}$ and $\mathrm{He}$, and identical initial PSDs - namely

467 the one measured in the $\mathrm{N}_{2}$ case, were used. This numerical investigation strengthens the

468 important role of temperature in oxidation-induced fragmentation.

469 4.2. The effect of fuel lean and fuel rich condition

470 Previous studies showed the importance of fragmentation in fuel-lean conditions where 471 molecular oxygen plays a key role. In this section results from a fuel-rich second burner are 472 presented to understand the role of oxidation-induced fragmentation under this condition. The 473 results are compared with the reference case, fuel-lean, $\mathrm{N}_{2}$ as diluent.

474 Changing the equivalence ratio in the second burner resulted in changing the concentration of $475 \mathrm{O}_{2}$ which directly affects the temperature and combustion chemistry. In the previous section, it 476 was found that oxidation-induced fragmentation was strongly dependent on the temperature 477 while the gas species profiles were kept similar for all the flames. The temperature profile 478 measured in the fuel-rich case is reported in the Fig. 5 together with the reference case. The 479 temperature in the rich flame was lower than in lean $\mathrm{N}_{2}$ case, namely, 50K less than the reference 480 case, and the location of maximum temperature was shifted toward the burner. Also, the fuel-rich 
case temperature was higher than the He case previously presented (about $30 \mathrm{~K}$ ).

482 In Fig. 6, the measured and predicted gas profiles for the fuel-rich case (left panel) are 483 reported against residence time. For the sake of clarity, the reference case gas profiles are 484 reported as well (right panel). The modeled profiles were shifted away from the burner by $4852.5 \mathrm{~mm}$ as previously described. Gas concentration profiles show that $\mathrm{O}_{2}$ concentration was 486 initially higher for the lean case than for the rich case, the latter exhibiting an oxygen 487 concentration of $2-4 \%$ in the main reaction zone.

488 In Fig. 7, measured and modeled PSDs for the lean $\mathrm{N}_{2}$ case and fuel-rich case are reported. 489 The model predictions were in good agreement with experimental data, especially in matching 490 when the oxidation-induced fragmentation became effective. In the fuel-rich case (right), the 491 initial PSD was similar to the one measured in lean cases: the PSD was centered on 40nm, and 492 there were no particles smaller than $4 \mathrm{~nm}$ mobility diameter. The increase in number 493 concentration of the small particles in the rich case was present at 1.6 and $2.4 \mathrm{~mm}$ and persisted 494 along the flame. Finally, the particle concentration was reduced, but a complete burnout was not 495 reached. The rise in the number concentration of the small particles was a net effect of the 496 competition between oxidation-induced fragmentation and global oxidation. Due to overall rich 497 conditions, global oxidation was slower, and molecular oxygen contributed at lower flame 498 heights where it was present. As the flame front was passed, the oxidation was mainly due to $\mathrm{OH}$ 499 radical, since molecular oxygen was present in negligible concentrations. In the fuel-rich case, 500 small particles reached higher concentrations as compared to the lean N2 case where they were 501 continuously oxidized.

\section{4.3. Sensitivity analysis}

503 A sensitivity analysis is presented to understand the role of the different pathways in the 
504 oxidation-induced fragmentation process. The lean $\mathrm{N}_{2}$ case was chosen due to the apparent 505 presence of the rise in the number concentration of small particles as well as the presence of 506 complete burn out at the end of the flame. The two different mechanisms of oxidation-induced 507 fragmentation, namely aggregate fragmentation and single-particle fragmentation were 508 alternatively removed from the model to investigate their role.

509 In Fig. 8, modeled PSDs obtained with the complete model (continuous line), as well as those 510 obtained from "switching off" the oxidation-induced fragmentation mechanisms are reported and 511 compared with experimental PSDs. It is possible to see that the switching off the different 512 mechanisms of oxidation-induced fragmentation resulted in different PSD trends. In particular, 513 just accounting for the aggregate fragmentation cannot explain the rise in the particles smaller 514 than $5 \mathrm{~nm}$. These small particles must come from single particle fragmentation. In Fig. 8 the 515 modeled PSDs produced with aggregates fragmentation only (dashed line, center panels) 516 followed the complete model for the large particles earlier in the flame- up to $2.4 \mathrm{~mm} \mathrm{HAB}$ - but 517 it produced a unimodal distribution. Also, the size of the larger particles decreased overall, but 518 the modeled PSDs failed to match the experimental data. These findings are in accordance with a 519 similar sensitivity analysis previously conducted [33].

520 On the other hand, when accounting solely for single particle fragmentation (dotted line, left 521 panels), the first increase in number concentration (between $1.6 \mathrm{~mm}$ and $2.4 \mathrm{~mm}$ in the Fig. 8) was 522 predicted. However, once all these particles were consumed (at $3.2 \mathrm{~mm}$ in the Fig. 8), the number 523 concentration suddenly decreased, not matching the complete model and the experimental data. 524 Moreover, this model completely failed to match the change in the size of the large particles and 525 burnout.

526 Finally, when both mechanisms of oxidation-induced fragmentation were switched off (long 
527 dashed line, right panels), the model which accounts for the single particle fragmentation and the

528 model without any fragmentation collapsed for larger particles at higher heights above the

529 burner. These results suggest that the complete model cannot be considered as just the sum of the

530 two mechanisms since a synergistic effect was present. Aggregate fragmentation gradually

531 produced smaller aggregates, and eventually single particles, which were, in turn, fragmented,

532 producing smaller particles. In addition, global oxidation was taking place, competing with the

533 fragmentation mechanisms and contributing to particle burn out.

\section{5. Conclusions}

536 A systematic study of the effect of temperature and oxygen mixing on oxidation-induced

537 fragmentation of soot aggregates and particles has been conducted. Soot particle size

538 distributions, measured during the oxidation process in a two-stage burner [30], were modeled

539 with a Multi-Sectional method that accounts for oxidation-induced fragmentation. The model

540 parameters had been previously tested in premixed and diffusion flames. Without changing any

541 parameters, the model reproduced the evolution of PSD over a wide range of temperature and 542 oxygen-mixing conditions quite closely.

543 Overall the model suggests that oxidation-induced fragmentation processes and the oxidation

544 rates were very sensitive to the temperature. A decrease in temperature can induce a global

545 slowdown of the oxidation process. As a net result, oxidation-induced fragmentation produced a

546 large number of small particles, not completely oxidized. On the contrary, an increase of

547 temperature can enhance the global oxidation process and small particles produced by oxidation-

548 induced fragmentation were quickly oxidized. Fuel-rich and fuel-lean results suggest that in the

549 presence of relevant oxygen concentration, even for a short time, e.g., in the preheating zone of 
550 the investigated fuel-rich flame, oxidation-induced fragmentation took place. Small particles can

551 then be emitted if the complete oxidation is not reached. These local conditions can be likely

552 found in turbulent flames where there is a continuous mixing between the combustion by-

553 products and the fresh fuel/air mixture.

554 Finally, the sensitivity analysis conducted with the Multi-Sectional method indicated that

555 aggregate fragmentation dominates the process of mass reduction whereas particle fragmentation

556 was responsible for the increase of small particle number concentration. However, both

557 mechanisms were needed for the correct prediction of the evolution of particle size distribution.

558 The understanding of oxidation-induced fragmentation was aided by the use of the Multi-

559 Sectional model. In particular, the need for considering both aggregate and particle

560 fragmentation to follow the evolution of PSD during soot oxidation was clearly verified. Both

561 these process strongly influence the total burn out and the size of emitted particles and, as such,

562 should be included in models for soot prediction.

563

564 Acknowledgments

565 This material is based upon work supported by the National Science Foundation under Grant

566 No. 1133480 while Dr. Lighty served at the National Science Foundation. Any opinions,

567 findings, and conclusions expressed in this publication are those of the authors and do not 568 necessarily reflect the views of the National Science Foundation.

569 MS and AD'A acknowledge the financial support of Accordo di Programma MSE/CNR PAR

570 2013-2014 "Miglioramento dell'efficienza energetica dei sistemi di conversione locale di

571 energia". 
574 [1] H. Jander, H.G. Wagner, Soot formation in combustion, in: Int. Round Table Discuss. (Vandenhoeck Ruprecht, Gottingen), 1990.

576 [2] H.E. (Ed) Bockhorn, Soot Formation in Combustion (Mechanisms and Models), 1994.

[3] H. Bockhorn, A. D’Anna, A.F. Sarofim, H. Wang, (EDs.), Combustion Generated Fine Carbonaceous Particles, KIT Scientific Publishing, 2009. https://books.google.com/books?id=8-Dk399oJwUC.

[4] A. D’Anna, Combustion-formed nanoparticles, Proc. Combust. Inst. 32 (2009) 593-613.

[5] H. Wang, Formation of nascent soot and other condensed-phase materials in flames, Proc. Combust. Inst. 33 (2011) 41-67.

[6] P. Pedata, N. Bergamasco, A. D’Anna, P. Minutolo, L. Servillo, N. Sannolo, et al.,

[8] J.H. Seinfeld, S.N. Pandis, Editors., Atmospheric chemistry and physics: from air Apoptotic and proinflammatory effect of combustion-g
endothelial cells., Toxicol. Lett. 219 (2013) 307-314.

[7] P. Pedata, T. Stoeger, R. Zimmermann, R. Zimmermann, A. Peters, G. Oberdorster, et al., "Are we forgetting the smallest, sub $10 \mathrm{~nm}$ combustion generated particles?," Part. Fibre Toxicol. 12 (2015) 34.

[9] A. D’Anna, M. Sirignano, M. Commodo, R. Pagliara, P. Minutolo, An Experimental and Modelling Study of Particulate Formation in Premixed Flames Burning Methane, Combust. Sci. Technol. 180 (2008) 950-958.

[10] M. Sirignano, A. Collina, M. Commodo, P. Minutolo, A. D’Anna, Detection of aromatic hydrocarbons and incipient particles in an opposed-flow flame of ethylene by spectral and time-resolved laser induced emission spectroscopy, Combust. Flame. 159 (2012) 16631669.

[11] M. Alfè, B. Apicella, R. Barbella, A. Tregrossi, A. Ciajolo, Distribution of Soot Molecular Weight/Size along Premixed Flames as Inferred by Size Exclusion Chromatography, Energy \& Fuels. 21 (2007) 136-140.

[12] M. Alfè, B. Apicella, R. Barbella, J.N. Rouzaud, A. Tregrossi, A. Ciajolo, et al., Structure-property relationship in nanostructures of young and mature soot in premixed flames, Proc. Combust. Inst. 32 (2009) 697-704.

[13] A. D’Alessio, A.C. Barone, R. Cau, A. D’Anna, P. Minutolo, Surface deposition and coagulation efficiency of combustion generated nanoparticles in the size range from 1 to 
10 nm, Proc. Combust. Inst. 30 (2005) 2595-2603.

607

608

609

610

611

612

613

614

615

616

617

618

619

620

621

622

623

624

625

626

627

628

629

630

631

632

633

634

635

636

637

[14] A. D'Alessio, A. D'Anna, P. Minutolo, L.A. Sgro, A. Violi, On the relevance of surface growth in soot formation in premixed flames., Proc. Combust. Inst. 28 (2000) 2547-2554.

[15] M.D. Smooke, M.B. Long, B.C. Connelly, M.B. Colket, R.J. Hall, Soot formation in laminar diffusion flames., Combust. Flame. 143 (2005) 613-628.

[16] M.M. Maricq, N. Xu, The effective density and fractal dimension of soot particles from premixed flames and motor vehicle exhaust, J. Aerosol Sci. 35 (2004) 1251-1274.

[17] L.A. Sgro, A. Borghese, L. Speranza, A.C. Barone, P. Minutolo, A. Bruno, et al., Measurements of Nanoparticles of Organic Carbon and Soot in Flames and Vehicle Exhausts., Environ. Sci. Technol. 42 (2008) 859-863.

[18] J.S. Lighty, J.M. Veranth, A.F. Sarofim, Combustion Aerosols: Factors Governing Their Size and Composition and Implications to Human Health, J Air Waste Manag Assoc. 50 (2000) 1565-1622.

[19] B.R. Stanmore, J.F. Brilhac, P. Gilot, The oxidation of soot: a review of experiments, mechanisms and models, Carbon N. Y. 39 (2001) 2247-2268.

[20] A. Veshkini, S.B. Dworkin, M.J. Thomson, A soot particle surface reactivity model applied to a wide range of laminar ethylene/air flames., Combust. Flame. 161 (2014) 3191-3200.

[21] M. Frenklach, Reaction mechanism of soot formation in flames, Phys. Chem. Chem. Phys. 4 (2002) 2028-2037.

[22] N. Morgan, M. Kraft, M. Balthasar, D. Wong, M. Frenklach, P. Mitchell, Numerical simulations of soot aggregation in premixed laminar flames, Proc. Combust. Inst. 31 (2007) 693-700.

[23] M.S. Celnik, M. Sander, A. Raj, R.H. West, M. Kraft, Modelling soot formation in a premixed flame using an aromatic-site soot model and an improved oxidation rate, Proc. Combust. Inst. 32 (2009) 639-646.

[24] J. Nagle, R.F. Strickland-Constable, Oxidation of carbon between 1000 and $2000^{\circ} \mathrm{C}$, in: Proc. Conf. Carbon, 5th, 1961: pp. 154-164.

[25] K.G. Neoh, J.B. Howard, A.F. Sarofim, Soot oxidation in flames., in: Proceeding Combust. Inst., Plenum, 1981: pp. 261-282.

[26] K.G. Neoh, J.B. Howard, A.F. Sarofim, Effect of Oxidation on the Physical Structure of Soot, in: Proceeding Combust. Inst., 1985: pp. 951-957. 
[27] C.A. Echavarria, I.C. Jaramillo, A.F. Sarofim, J.S. Lighty, Burnout of soot particles in a two-stage burner with a JP-8 surrogate fuel, Combust. Flame. 159 (2012) 2441-2448.

[28] C.A. Echavarria, I.C. Jaramillo, A.F. Sarofim, J.S. Lighty, Studies of soot oxidation and

[29] H. Ghiassi, P. Toth, J.S. Lighty, Sooting Behaviors of n-Butanol and n-Dodecane Blends, fragmentation in a two-stage burner under fuel-lean and fuel-rich conditions, Proc. Combust. Inst. 33 (2011) 659-666.

[30] H. Ghiassi, P. Toth, I.C. Jaramillo, J.S. Lighty, Soot oxidation-induced fragmentation: Part 2: Experimental investigation of the mechanism of fragmentation, Combust. Flame. 163 (2015) 170-178.

[31] H. Ghiassi, P. Toth, I.C. Jaramillo, J.S. Lighty, Soot oxidation-induced fragmentation: Part 1: The relationship between soot nanostructure and oxidation-induced fragmentation,

[32] M.E. Mueller, G. Blanquart, H. Pitsch, Modeling the oxidation-induced fragmentation of Combust. Flame. 163 (2015) 179-187.

[33] M. Sirignano, J. Kent, A. D'Anna, Modeling formation and oxidation of soot in nonpremixed flames, Energy \& Fuels. 27 (2013) 2303-2315.

[34] M. Sirignano, J. Kent, A. D'Anna, Further experimental and modelling evidences of soot fragmentation in flames, Proc. Combust. Inst. 35 (2015) 1779-1786.

[35] H. Ghiassi, I.C. Jaramillo, J.S. Lighty, Kinetics of soot oxidation by molecular oxygen in a premixed flame, Energy \& Fuels. (2016).

[36] S.J. Harris, M.M. Maricq, The role of fragmentation in defining the signature size distribution of diesel soot, J. Aerosol Sci. 33 (2002) 935-942.

[37] Q. Zhang, M.J. Thomson, F. Guo, H.; Liu, G.J. Smallwood, Modeling of OxidationDriven Soot Aggregate Fragmentation in a Laminar Coflow Diffusion Flame, Combust. Sci. Technol. 182 (2010) 491-504.

[38] R. Puri, T.F. Richardson, R.J. Santoro, R.A. Dobbins, Aerosol dynamic processes of soot aggregates in a laminar ethene diffusion flame, Combust. Flame. 92 (1993) 320-323.

[39] F. Xu, A.M. El-Leathy, C.H. Kim, G.M. Faeth, Soot surface oxidation in hydrocarbon/air diffusion flames at atmospheric pressure, Combust. Flame. 132 (2003) 43-57.

[40] C.P. Fenimore, G.W. Jones, Oxidation of soot by hydroxyl radicals, J. Phys. Chem. A. 71 (1967) 593-597. 
[41] M.E. Mueller, Q.N. Chan, N.H. Qamar, B.B. Dally, H. Pitsch, Z.T. Alwahabi, et al., Experimental and computational study of soot evolution in a turbulent nonpremixed bluff body ethylene flame., Combust. Flame. 160 (2013) 1298-1309.

[42] A. Attili, F. Bisetti, M.E. Mueller, H. Pitsch, Formation, growth, and transport of soot in a three-dimensional turbulent non-premixed jet flame., Combust. Flame. 161 (2014) 18491865.

[43] A.R. Kerstein, B.F. Edwards, Percolation model for simulation of char oxidation and fragmentation time-histories., Chem. Eng. Sci. 42 (1987) 1629-1634.

[44] R. Chirone, L. Massimilla, P. Salatino, Comminution of carbons in fluidized bed combustion, Prog. Energy Combust. Sci. 17 (1991) 297-326.

[45] M. Sirignano, J. Kent, A. D'Anna, Detailed modeling of size distribution functions and hydrogen content in combustion-formed particles, Combust. Flame. 157 (2010) 12111219.

[46] A. D'Anna, M. Sirignano, J. Kent, A model of particle nucleation in premixed ethylene flames, Combust. Flame. 157 (2010) 2106-2115.

[47] M. Sirignano, M. Alfè, A. Tregrossi, A. Ciajolo, A. D’Anna, Experimental and modeling study on the molecular weight distribution and properties of carbon particles in premixed sooting flames, Proc. Combust. Inst. 33 (2011) 633-640.

[48] M. Sirignano, M. Conturso, A. D'Anna, Effect of furans on particle formation in diffusion flames: An experimental and modeling study, Proc. Combust. Inst. 35 (2015) 525-532.

[49] G. Blanquart, H. Pitsch, Analyzing the effects of temperature on soot formation with a joint volume-surface-hydrogen model, Combust. Flame. 156 (2009) 1614-1626.

[50] S. Mosbach, M.S. Celnik, A. Raj, M. Kraft, H.R. Zhang, S. Kubo, et al., Towards a detailed soot model for internal combustion engines, Combust. Flame. 156 (2009) 11561165 .

[51] S.B. Dworkin, Q. Zhang, M.J. Thomson, N.A. Slavinskaya, U. Riedel, Application of an enhanced PAH growth model to soot formation in a laminar coflow ethylene/air diffusion flame, Combust. Flame. 158 (2011) 1682-1695.

[52] A. Raj, M. Celnik, R. Shirley, M. Sander, R. Patterson, R. West, et al., A statistical approach to develop a detailed soot growth model using PAH characteristics, Combust. Flame. 156 (2009) 896-913.

[53] A. Raj, M. Sander, V. Janardhanan, M. Kraft, A study on the coagulation of polycyclic aromatic hydrocarbon clusters to determine their collision efficiency, Combust. Flame. 157 (2010) 523-534. 
[54] M. Sander, R.I.A. Patterson, A. Braumann, A. Raj, M. Kraft, Developing the PAH-PP soot particle model using process informatics and uncertainty propagation, Proc. Combust. Inst. 33 (2011) 675-683.

[55] T.S. Totton, D. Chakrabarti, A.J. Misquitta, M. Sander, D.J. Wales, M. Kraft, Modelling the internal structure of nascent soot particles, Combust. Flame. 157 (2010) 909-914.

[56] A. D'Anna, A. Violi, Detailed Modeling of the Molecular Growth Process in Aromatic and Aliphatic Premixed Flames, Energy \& Fuels. 19 (2005) 79-86.

[57] A. D'Anna, Detailed Kinetic Modeling of Particulate Formation in Rich Premixed Flames of Ethylene, Energy \& Fuels. 22 (2008) 1610-1619.

[58] K.G. Neoh, Soot burnout in flames, Massachusetts Institute of Technology, 1980. http://hdl.handle.net/1721.1/15866.

[59] H. Ghiassi, Soot oxidation and the mechanisms of oxidation-induced fragmentation in a two-stage burner for ethylene and surrogate fuels, Utah, 2015.

[60] C. McEnally, Ü. Köylü, L.D. Pfefferle, D.E. Rosner, D.C.S. McEnally, U.O. Koylu, et al., Soot volume fraction and temperature measurements in laminar non-premixed flames using thermocouples, Combust. Flame. 109 (1997) 701-720.

[61] B. Zhao, Z. Yang, J. Wang, M. V. Johnston, H. Wang, Analysis of soot nanoparticles in a laminar premixed ethylene flame by scanning mobility particle sizer, Aerosol Sci. Technol. 37 (2003) 611-620.

[62] B. Zhao, Z. Yang, M. V Johnston, H. Wang, A.S. Wexler, M. Balthasar, et al., Measurement and numerical simulation of soot particle size distribution functions in a laminar premixed ethylene-oxygen-argon flame, Combust. Flame. 133 (2003) 173-188.

[63] P. Minutolo, A. D'Anna, M. Commodo, R. Pagliara, G. Toniato, C. Accordino, Emission of fine particles from natural gas domestic burners, Environ. Eng. Sci. 25 (2008) 13571363.

[64] A. Kazakov, M. Frenklach, Dynamic Modeling of Soot Particle Coagulation and Aggregation: Implementation With the Method of Moments and Application to HighPressure Laminar Premixed Flames, Combust. Flame. 114 (1998) 484-501.

[65] R.A. Dobbins, C.M. Megaridis, Morphology of flame-generated soot as determined by thermophoretic sampling, Langmuir. 3 (1987) 254-259.

[66] S. Will, S. Schraml, K. Bader, A. Leipertz, Performance characteristics of soot primary particle size measurements by time-resolved laser-induced incandescence., Appl. Opt. 37 (1998) 5647-5658. 
[67] M. Lapuerta, F.J. Martos, J.M. Herreros, Effect of engine operating conditions on the size of primary particles composing diesel soot agglomerates., J. Aerosol Sci. 38 (2007) 455466.

[68] M. Commodo, L.A. Sgro, P. Minutolo, A. D’Anna, Characterization of CombustionGenerated Carbonaceous Nanoparticles by Size-Dependent Ultraviolet Laser Photoionization., J. Phys. Chem. A. 117 (2013) 3980-3989.

[69] M. Commodo, G. De Falco, A. Bruno, C. Borriello, P. Minutolo, A. D'Anna, Physicochemical evolution of nascent soot particles in a laminar premixed flame: from nucleation to early growth., Combust. Flame. 162 (2015) 3854-3863.

[70] C.A. Echavarria, A.F. Sarofim, J.S. Lighty, A. D'Anna, Evolution of soot size distribution in premixed ethylene/air and ethylene/benzene/air flames: Experimental and modeling study, Combust. Flame. 158 (2011) 98-104. 
Table 1. Experimental conditions.

\begin{tabular}{lcccc}
\hline & $\emptyset_{1}^{a}$ & $\emptyset_{\text {Overall }}^{b}$ & $\vartheta^{c}$ & $\begin{array}{c}\text { Secondary } \\
\text { oxidizer composition }\end{array}$ \\
\hline Lean $\mathrm{N}_{2}$ diluent (base case) & 1.98 & 0.9 & 3.77 & $21 \% \mathrm{O}_{2}-79 \% \mathrm{~N}_{2}$ \\
Lean Ar diluent & 1.98 & 0.9 & 3.77 & $21 \% \mathrm{O}_{2}-79 \% \mathrm{Ar}$ \\
Lean He diluent & 1.98 & 0.9 & 3.77 & $21 \% \mathrm{O}_{2}-79 \% \mathrm{He}$ \\
Rich $\mathrm{N}_{2}$ diluent & 1.98 & 1.15 & 3.77 & $21 \% \mathrm{O}_{2}-79 \% \mathrm{~N}_{2}$ \\
\hline
\end{tabular}

${ }^{\mathrm{a}}$ Equivalence ratio in the first burner

${ }^{\mathrm{b}}$ Overall Equivalence ratio

${ }^{c}$ Cold gas velocity, cm/s (STP) 


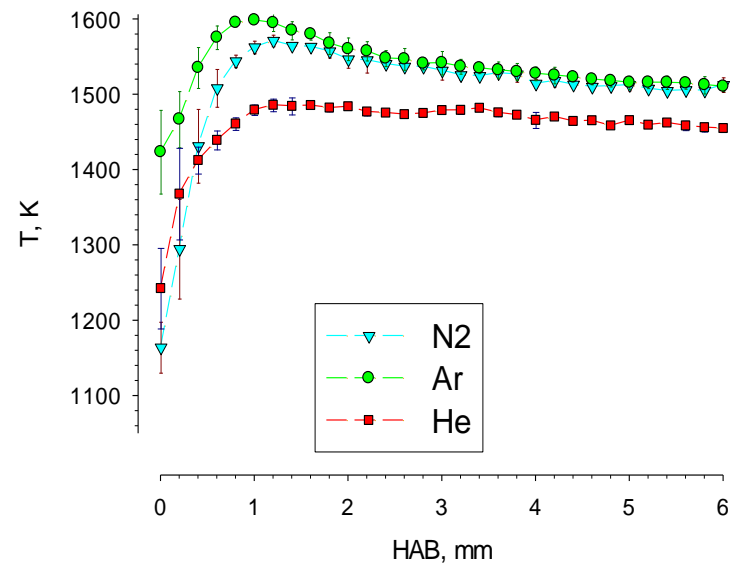

Fig. 1. Top burner temperature profiles as a function of $H A B$ for the three different cases investigated: Ar diluent - highest flame temperature, N2 diluent - medium flame temperature, He diluent - lowest flame temperature. Adapted from [30]. 


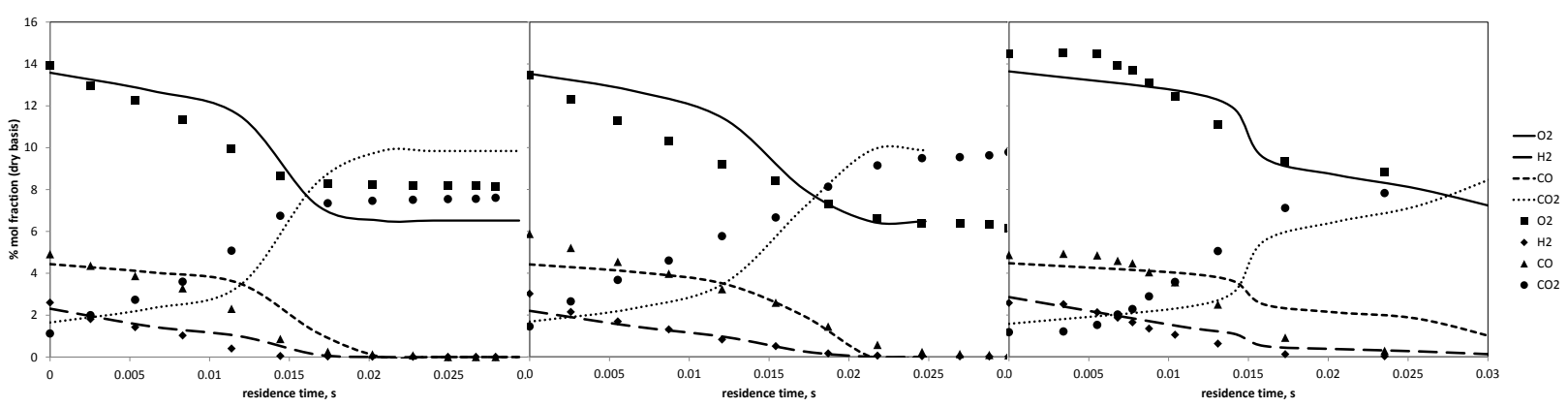

Fig. 2. Species concentration profiles measured at different residence time in the top burner for the three different case investigated [30]: Ar diluent - highest flame temperature (left), N2 diluent - medium flame temperature (center), He diluent - lowest flame temperature (right). Model predictions are reported as continuous lines. 

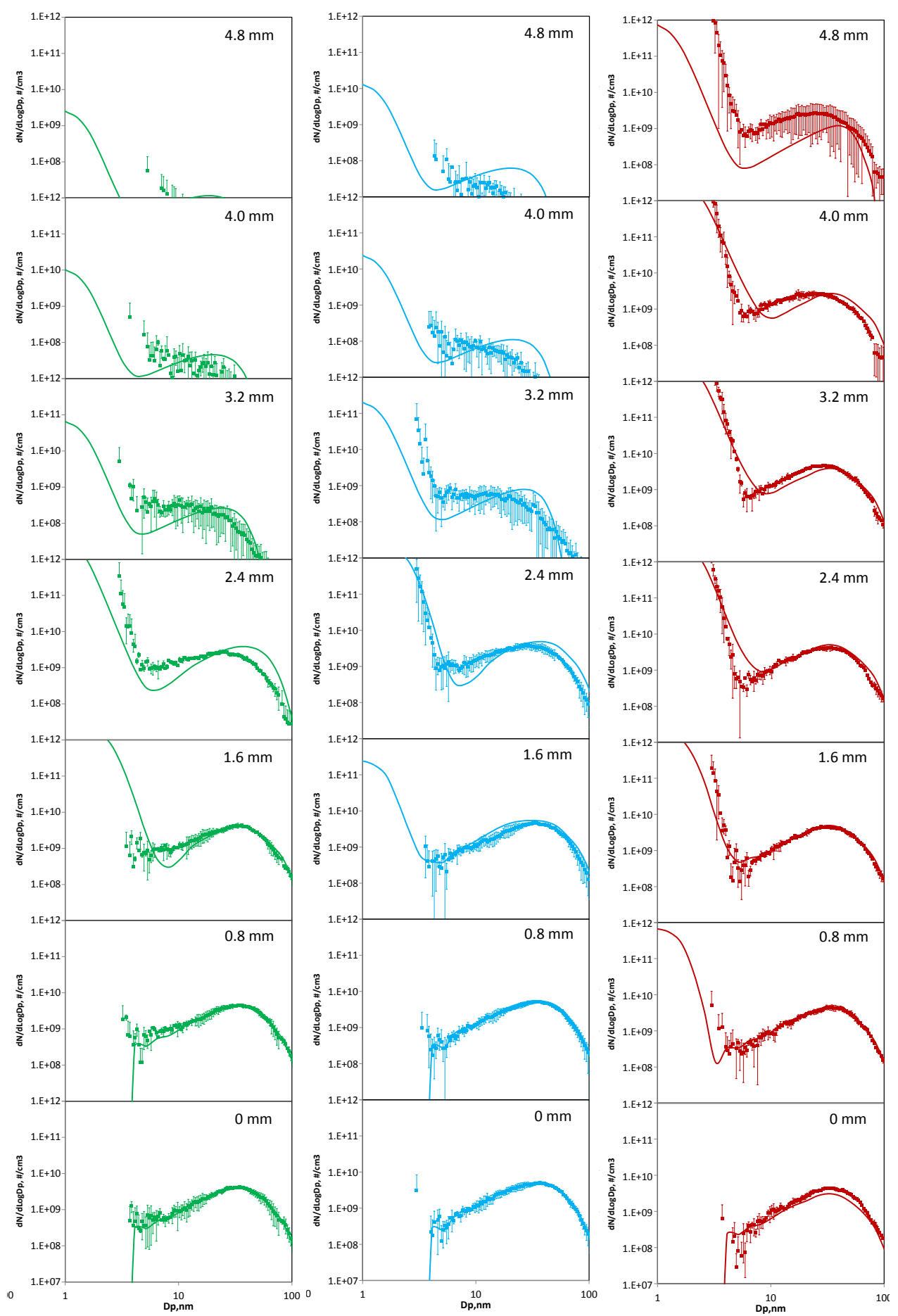

Fig. 3. PSDs measured at different heights above the top burner (from the bottom: $0,0.8,1.6$, 2.4, 3.2, 4.0 and 4.8mm HAB) for the three different case investigated: Ar diluent - highest flame temperature (green - left), $\mathrm{N}_{2}$ diluent - medium flame temperature (blue - center), He diluent - lowest flame temperature (red - right). Model predictions are reported as continuous lines. 


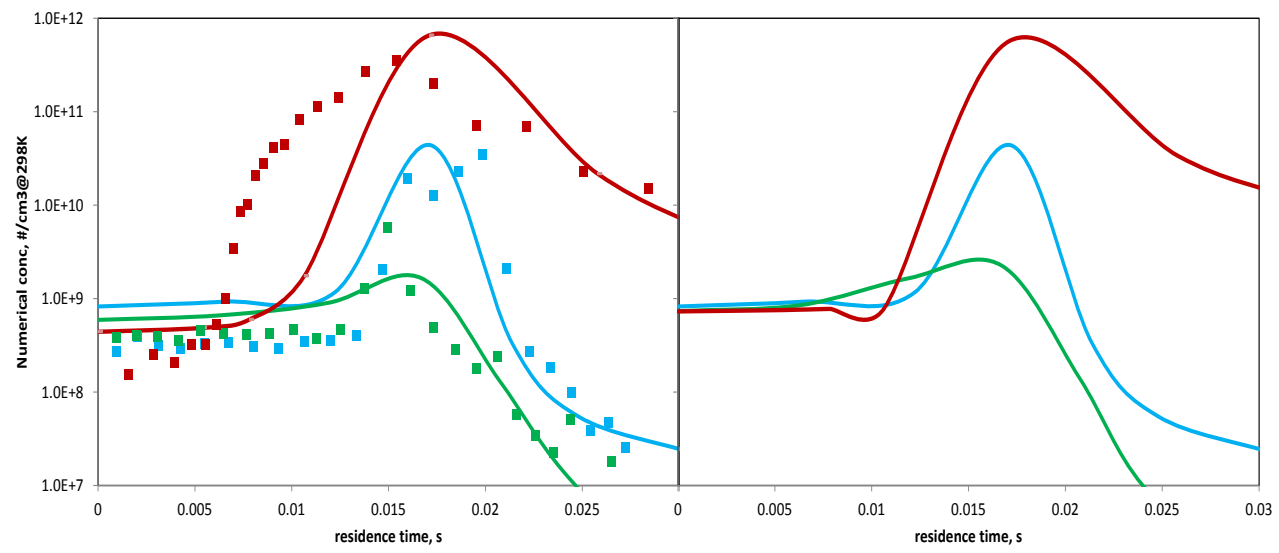

Fig. 4. Modeled integrated number concentration of particles between $3 \mathrm{~nm}$ and $10 \mathrm{~nm}$ at different residence time in the top burner for the three different case investigated [30]: Ar diluent - highest flame temperature (continuous line green), $\mathrm{N}_{2}$ diluent - medium flame temperature (continuous line blue), He diluent - lowest flame temperature (continuous line red) compared with experimental data (symbols); left. Right, model predictions using the same temperature profiles as the results on the left, but $\mathrm{N}_{2}$ as diluent and same initial PSD for all cases. 


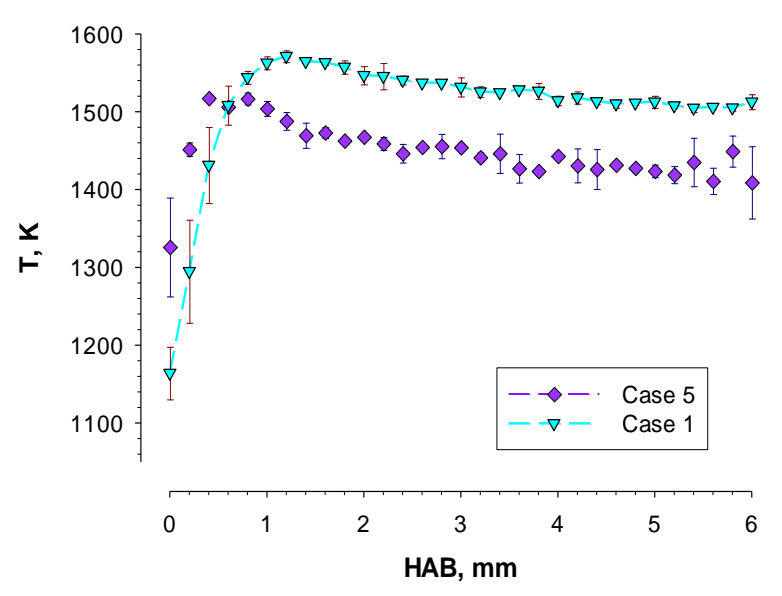

Fig. 5. Top burner temperature profiles as a function of $\mathrm{HAB}$ for the rich and lean $\left(\mathrm{N}_{2}\right.$ as diluent) case investigated. Adapted from [30].

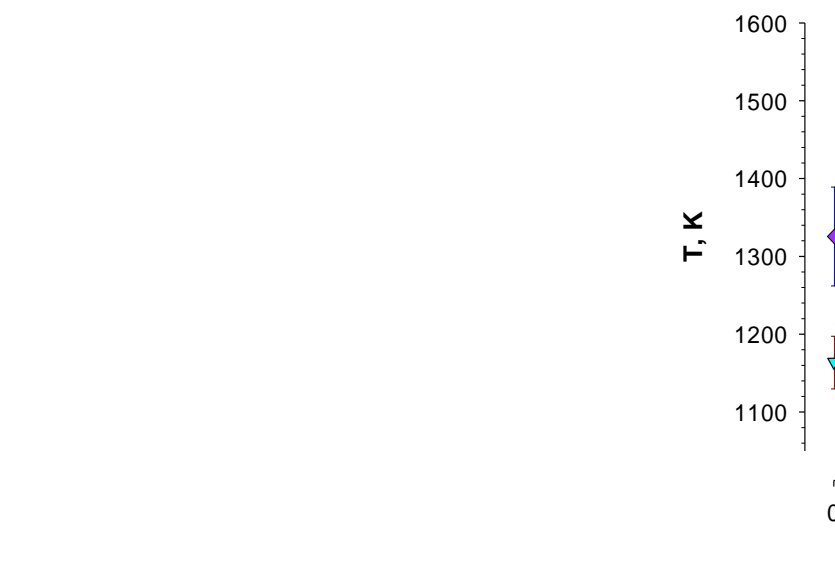

HAB, mm

)

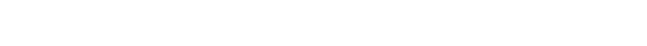

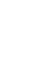




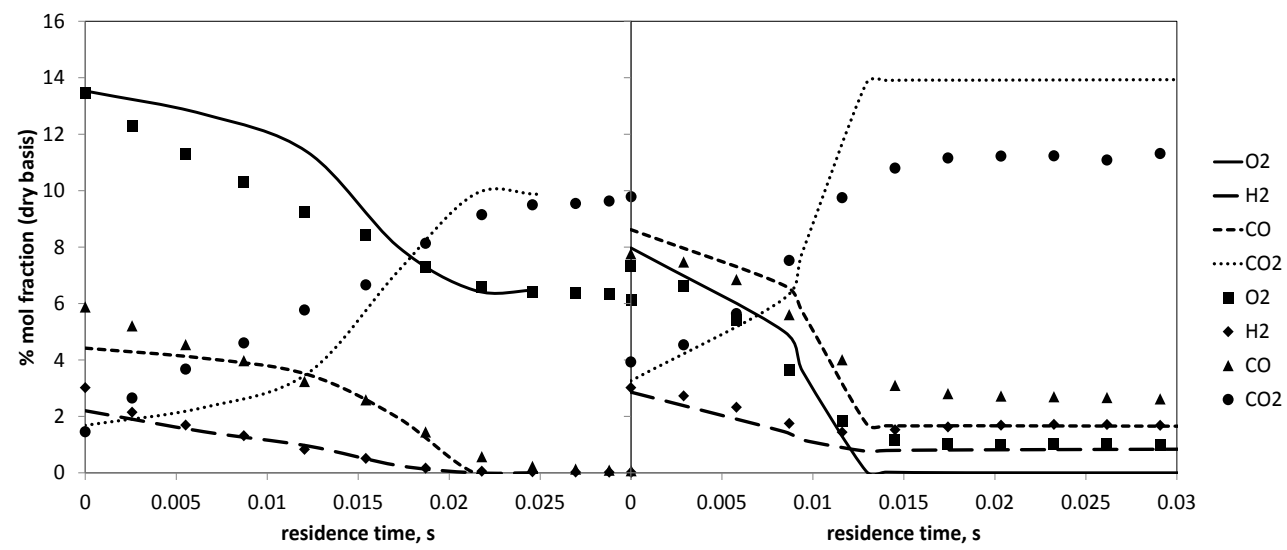

Fig. 6. Species concentration profiles measured at different residence time in the top burner for the rich (right) and lean (N2 as diluent, left) case investigated [30]. Model predictions are reported as continuous lines. 

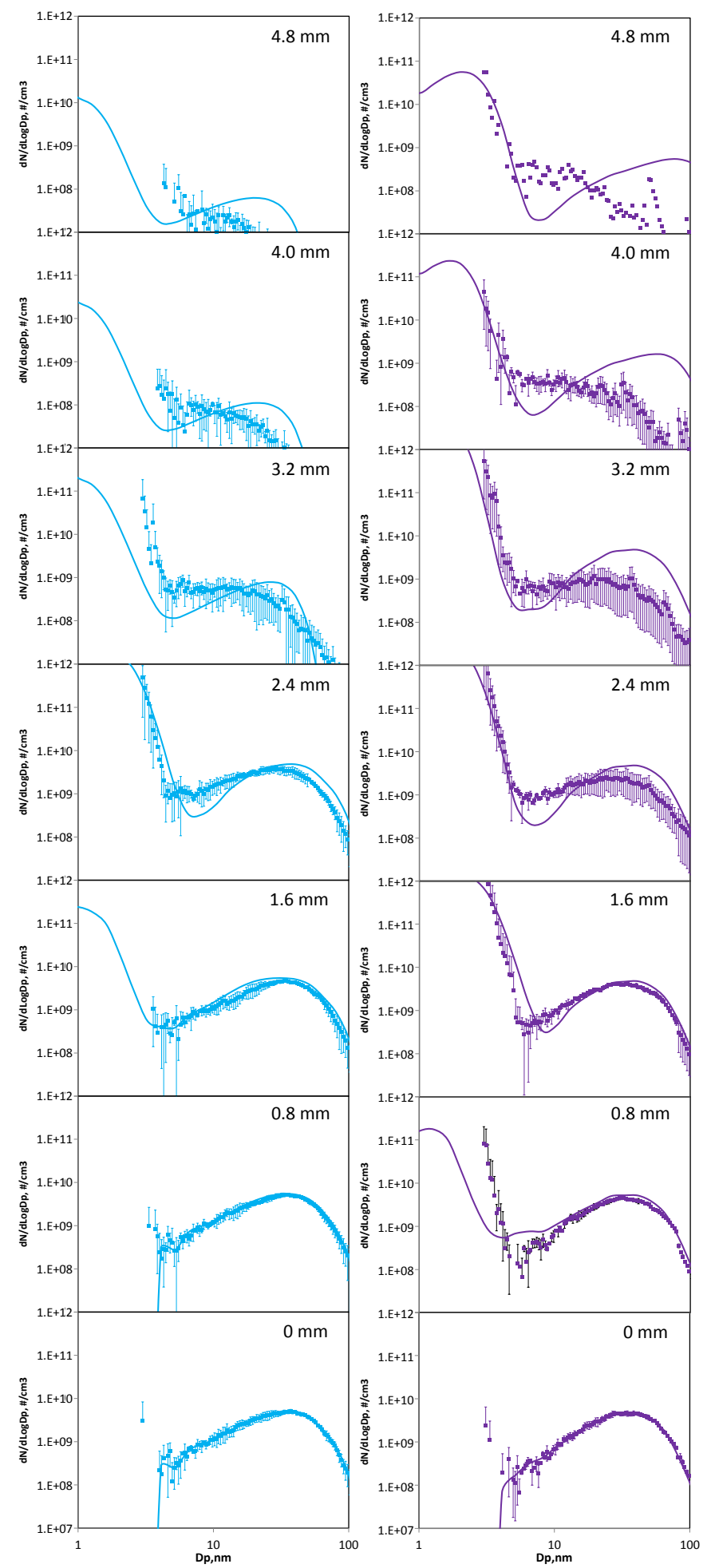

Fig. 7. PSDs measured at different heights above the top burner (from the bottom: $0,0.8,1.6$, 2.4, 3.2, 4.0 and 4.8mm HAB) for the lean $\left(\mathrm{N}_{2}\right.$ as diluent, left [30]) and rich (right) cases investigated. Model predictions are reported as continuous lines. 


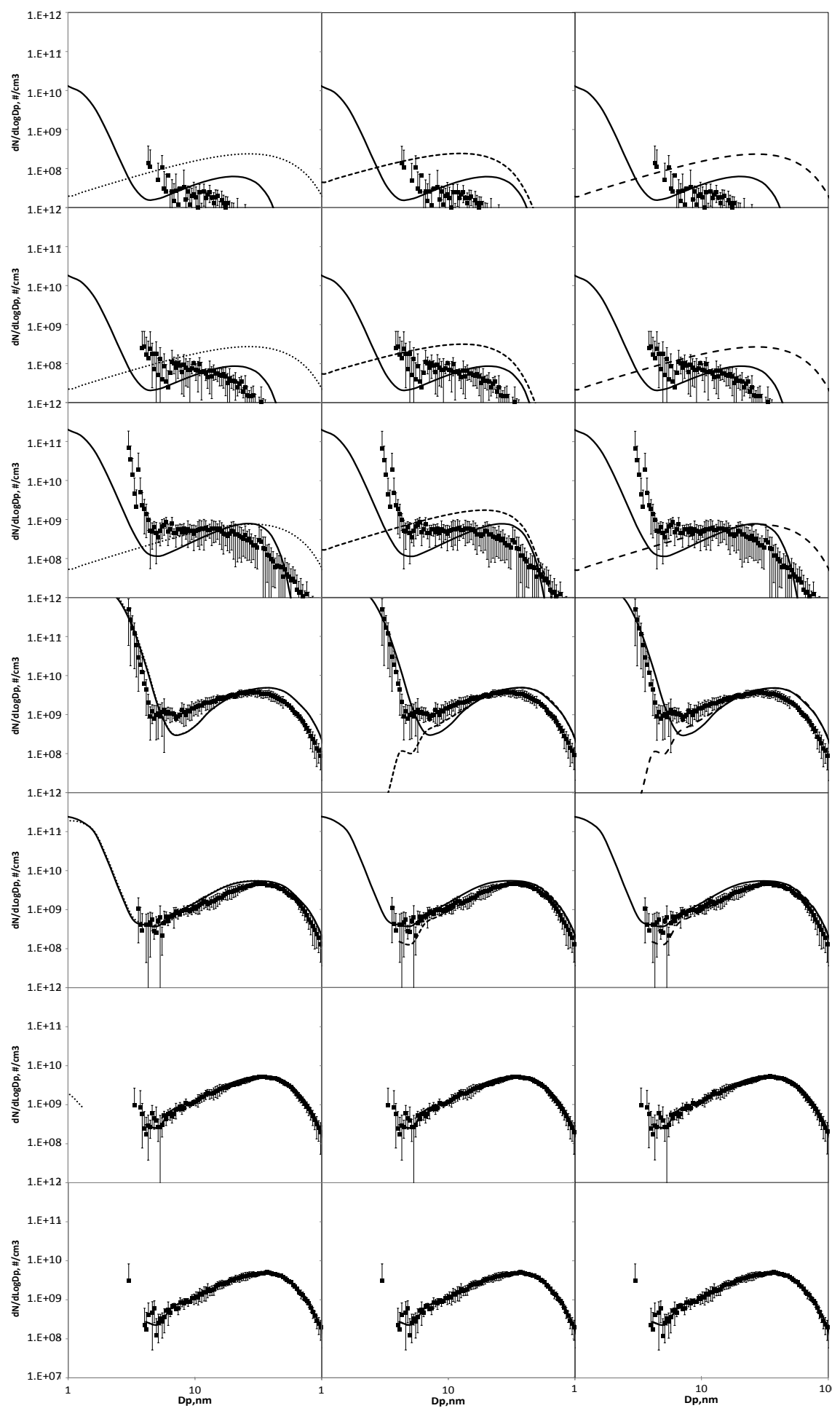

Fig. 8. PSDs measured at different heights above the top burner (from the bottom: 0, 0.8, 1.6, 2.4, 3.2, 4.0 and 4.8mm HAB) for the lean case using $\mathrm{N}_{2}$ as diluent [30]. Model predictions obtained with different fragmentation models are reported: complete model (continuous line); only particle fragmentation (dotted line - left column); only aggregate fragmentation (dashed line - center column) no fragmentation (long dashed line - right column). 